\title{
Noncanonical Constructions in English and How They Work to Package Information
}

\author{
Ikmi Nur Oktavianti \\ Universitas Ahmad Dahlan \\ ikmi.oktavianti@pbi.uad.ac.id
}

\begin{abstract}
Linguistic construction embodies information that is plausible to be modified in certain context when the speaker wants to emphasize on certain aspect. This is the nature of language users and the construction they produce. Each language is assumed to possess its own various ways of structuring the information spoken or written by the language user. English, for example, which is known as fixed word order language with SVO order has its various ways of structuring the information delivered by the speaker to the interlocutor. Preposing, postposing, and argument reversal are three best ways to indicate which information is prominent in the speaker's mind so that the hearer will have the same concept as the speaker. Those are included as the alternative ways to construct sentence and propose syntactic choices to the speaker. Information structure has been one of the most intriguing fields of study involving both syntactic and pragmatic analyses. Hence, this paper aims at describing the noncanonical constructions in English and how they work to package information by using the interface of both disciplines.
\end{abstract}

Keywords: noncanonical construction, information structure, discourse

\section{Introduction}

Language users speak the language not only by constructing linguistic unit but also by putting the information in its appropriate place. The placement of the information is important to make the prominent one understandable by the hearer or interlocutor so that the delivery of the message can be successful. Since the realization of linguistic unit in communication is sentence and sentence belongs to syntactic unit, thus the discussion of information structure (the delivery of message) deals with syntactic construction. Finegan (2008) mentioned that syntactic 
construction embodies two types of information, namely semantic information and pragmatic information. Semantic information deals with the semantic aspect of the argument in the construction that gives information on the role of the argument.

\section{(1) John kicked the ball.}

Considering the semantic information of sentence (1), NP John is the agent (of the action), while NP the ball is the patient (of the action).

In addition, there is also pragmatic information embodied by linguistic construction. Pragmatic information refers to the type of the information. In other words, pragmatic information is related to given or new information.

(1) John kicked the ball.

(2) It broke the window.

If sentence (2) is the continuation of sentence (1), it in that sentence, then, is labeled as given information since it has been mentioned through its antecedent the ball. Based on the previous explanation, information can be defined as relative salience of the elements in a message (Crystal, 2008:245) in which message is syntactically called a construction. Information is one of categories embodied by NPs (arguments or participants) in a construction.

The discussion of this paper focused on pragmatic information, as many other information structure discussions have been done. Thus, it is related to the status of the NPs in the construction whether it is old or new or prominent. It is obvious that native speaker of a language has the ability to make certain information more prominent, thus there will be various syntactic constructions to refer to the same meaning (Birner and Ward, 1998; Finegan, 2008). The condition is called as syntactic choice in which a speaker has his own right to determine the construction according to the context he wants to create. It is because he is already exposed to the language for ages and he has the tacit knowledge of the language. It is also related to the effort of making the message delivered well to the interlocutor.

Since pragmatic information is about the NP status in the construction, information structure deals with the structuring of participant or argument and the perspective toward the participant (Foley via Shopen, 2007).

(3) Fred gave a book to Samantha.

(3a) Samantha has been given a book by Fred.

Both sentence (3) and (3a) has the same verb give, but with different instantiation. The first one, Fred, the agent, is the prominent information. 
Whereas, in the latter, Samantha-the patient of the action-is the prominent information. This could happen because the perspective of the participant is changed.

However, given/new information is not only limited to participant or argument but also cover information as the following.

(4) A: Kamu beli topi di mana?

B : (Beli topi di) Beringharjo.

Constituent beli topi di is categorized as given information because it has been mentioned in the previous context so that without repeating the constituents speaker and hearer already know what the discussion is about. The hearer, then, may only say the new information Beringharjo.

Considering that each language has its own characteristics, it is obvious then that each language has its own realization on structuring the information. Thus, it is intriguing to describe further the ways of information packaging in English. Since information packaging mostly deals with noncanonical word orders, this paper will discuss those constructions as the main discussion to find out the way of information packaging.

\section{Canonical and Noncanonical Constructions}

English as a language with fixed word order has SVO in its clause/sentence pattern (Comrie, 1981). This pattern is then acceptable as the grammatical pattern of the sentence; the violence of this structure will result in ungrammatical sentence as in (5a) and (6a).

(5) My uncle builds a house.

(5a) *builds my uncle a house.

(6) I use toothbrush.

(6a) *toothbrush use I.

Sentence (5) and (6) is called canonical construction. Canonical construction can be defined as a linguistic form cited as a standard for purposes of comparison (Crystal, 2008:64). Thus, the canonical construction of each language will be different, e.g. Japanese will have SOV as its canonical pattern.

However, the sentence below is not following the SVO pattern but compare to sentence (7), it is not an ungrammatical sentence in English.

(7) Hamburger, I ate.

Sentence (7) is sort of sentence conveying the motivation of the speaker in delivering the message: which information is tried to be more exposed and less exposed. Sentence (7), then, can be called as noncanonical construction because the speaker violates its canonical construction to 
achieve certain purpose. Therefore, information packaging is often associated with noncanonical construction because by using this uncommon structure the information can be delivered based on the speaker's need or motivation.

There are several kinds of making the construction become noncanonical, including preposing the constituent, postposing the constituent, or reversing the argument (participant). Preposing is a canonically postverbal phrasal constituent appears in the preverbal position (Birner and Ward, 1998:31).

(8) Hamburger, I ate.

(9) English, I like.

NP hamburger and English-which are canonically in postverbal positionare fronted to the sentence-initial position to fulfill the pragmatic function in order to get the message delivered.

Meanwhile, postposing is any construction in which a lexically governed phrasal constituent appears in the right of its canonical position, typically but not exclusively in the sentence-final position, leaving its canonical position empty or else occupied by an expletive (Birner and Ward, 1998: 5). The following sentence moves its argument (subject) into the sentence-final position.

\section{(10)She's a smart cookie, that Diana!}

Another way to noncanonically transform a construction is by reversing the argument. Argument reversal incorporates both preposing and postposing (Barner and Ward, 1998:6). Argument reversal in English can be found in by-phrase passive construction. By-phrase passive contains logical subject but it is placed in postverbal position.

(11) That offer was rejected by Connaught.

NP That offer fills the position of syntactic subject-which canonically the object of the sentence-that semantically is not the agent of the action. By-phrase constituent by Connaught is the logical subject which refers to the logical subject of the action. There is a process of reversing the logical subject with the object as it can be seen from its canonical sentence.

(12) Connaught rejected that offer.

Nevertheless, according to Birner and Ward (1998:5-6) leftdisclocation and right-dislocation is not included as preposing and postposing due to syntactical and functional difference. To make this discussion comprehensive, the differences and the reasons will not be elaborated in this paper. Besides, the discussions on noncanonical 
construction will be limited to several sorts, such as topicalization, existential there, left-dislocation, right-dislocation, and cleft/pseudo-cleft construction.

\section{Information Structure}

Information structure is the interface of syntax and pragmatics (discourse function) because it works in the syntactic level but it is related to presupposition and context (Birner and Ward, 1998). Every preposition can be expressed in a number of ways; however, speakers do not choose randomly from among these options or called as syntactic choice. According to Creswell (2004:1), syntactic choice is linked with the choice of information packaging based on the nature of the speaker as free being.

(13) It was Ed that grilled the steak.

(13a) It was the steak that Ed grilled.

(13b) What happened was Ed grilled the steak.

The term 'packaging' was once proposed by Chafe (1976) to refer to syntactic structuring to meet the pragmatic function. In line with Chafe, Vallduvi (1992) stated that the purpose of information packaging is to maximize the entry of data into the hearer's knowledge.

One category of information structure is the distinction between given and new information. Finegan (2008:251) mentioned that given information is the kind of information that currently in the forefront's of the hearer's mind, while new information is sort of information that just being introduced in the context (to the hearer).

(14) Who closed the door?

Ali closed the door.

In the example above, Ali represents new information since it is being introduced in the discourse; by contrast, the door is given information because it has been mentioned in the previous discourse.

Related to the concept of information and the consideration that information is related to context (discourse/hearer), thus, there are several types of information in the analysis of information structure, namely 1) hearer-old, discourse old, 2) hearer-old, discourse-new, 3) hearer-new, discourse-new, and 4) hearer-old, discourse-old (Birner and Ward, 1998:15). The following sentence will help the elaboration of each information type.

(15)Last night the moon was so pretty that I called a friend on the phone and told him to go outside and look. 
In sentence (15), NP the moon is the clear example of hearer-new but discourse-old information. Although it is not mentioned previously in the discourse, the speaker will assume the hearer that he already recognizes the entity since it is a general knowledge (world knowledge). Meanwhile, NP a friend in sentence (15) is discourse-new and hearer-new information because it is just being introduced in the discourse and the hearer does not know the information yet. Whereas, him is hearer-old and discourseold information since it has been mentioned in the previous NP a friend. In other words, him is the pronoun form of the NP a friend. According to Prince (1997), hearer-old and discourse-old information does not occur in the natural discourse.

\section{IV.Noncanonical Constructions in English}

Discussing noncanonical constructions, it cannot be separated to several constructions which are noncanonically used to meet the speaker's need. They include topicalization, extraposition, existensial there, left-dislocation, right-dislocation, cleft/pseudo-cleft construction, and many others. However, this paper will discuss the most frequently used and the most productive noncanonical constructions in English. Furthermore, the discussion will also cover the way the construction package the information.

\section{1) Topicalization}

One way of information packaging is topicalization. Topicalization presents a topic NP juxtaposed immediately to the left of the clause (Foley via Shopen, 2007), as in the example below.

(16) The steak, Ed grilled.

That sentence is derived from the canonical construction as in (16a).

(16a) Ed grilled the steak.

$\mathrm{NP}$ the steak is fronted in the sentence-initial position, leaving its canonical position as the object of the sentence to achieve certain purpose of the delivery of the message. Another example can be seen in the following sentences.

(17) Do you like Belgian beer and Belgian wine?

Belgian beer, I like.

In the sentence above, Belgian beer is being fronted to sentence-initial position to emphasis on the choice (that the speaker likes Belgian beer).

Nevertheless, not all constituent can be moved leftward to sentence-initial position as in the example below. 
(18)*In Basket, I put your clothes.

Constituent in basket cannot be juxtaposed to the left part of the sentence due to its condition as lexically governed by the verb put. Lexically governed constituent cannot be independent in its movement (Barner and Ward, 1998). The verb put governs PP in basket as it can be observed in the canonical sentence below.

(18a) I put your clothes in basket.

Sentence (19) has rather different hierarchical structure, so that the PP in New York can be fronted.

(19) There are many things we can do in New York.

The noncanonical sentence above is transformed from the following canonical form.

(19a) We can do many things in New York.

To conclude, there are two types of constituents that meet the requirement of topicalization: object or lexically ungoverned constituent (PP). Constituents that are not lexically governed are less constrained with the ordering in a construction.

Not to forget to pragmatic function of topicalization, it aims at making certain information (NP) prominent as in example (16). Thus, the NP being fronted is the NP that embodies hearer-old and discourse-old information (Prince, 1997). New information (discourse-new, hearer-new) cannot be fronted.

\section{2) Existential there}

The discussion on noncanonical construction cannot be separated from existential there construction. Existential there is one of information packaging involves the postposing of constituent to the postverbal position in a sentence to meet certain pragmatic function of the speaker (Birner and Ward, 1998).

(20)There is a riot on Prince Street.

Sentence (20) consists of two elements: expletive there and its complement a riot on Prince Street as the focus of the message being delivered. There in that sentence is attempting to introduce the focus.

Expletive there in the sentence above is syntactic subject but semantically empty. It is derived from canonical sentence as the following.

(21) A riot is on Prince Street. 
Existential construction in (20) indicates the presence or existence of particular thing named 'riot' on certain place.

Existential there represents an entity which is assumed as hearernew information by the speaker (Prince, 1997).

(22) There was the stupidest article on the reading list.

The constituent the stupidest article is assumed as hearer-new information by the speaker and therefore it is the focus of the message being delivered.

It has to bear in mind that the interpretation of existential there is not limited to existence, but also to presence or locative interpretation. Comorovski et al. (2007:14) existential there can be interpreted as existence, presence, or locative.

(23) There is a rabbit in the garden.

(24) There is the student that you wanted to see in the corridor.

(25) There are three students in the common room.

Sentence (23) illustrates the interpretation of existential there as existence, sentence (24) indicates presence of thing or entity, and sentence (25) shows the locative interpretation.

\section{3) Left-dislocation}

Slightly observed, left-dislocation looks alike topicalization with its constituent being moved leftward to the sentence-initial position. Rather, left-dislocation is different from topicalization because the sentence-initial NP (the dislocated one) is co-referential with a pronoun (or full NP) within the sentence which occupies the canonical position of the initial NP (Creswell, 2004). According to Foley, left-dislocation can be distinguished form topicalization since there is the presence of pronominal element within the clause referring to the dislocated NP.

(16) Ed grilled the steak.

(16a) The steak, Ed grilled.

Sentence (16) is the canonical form of which it can be noncanonically transformed into topicalization as in (16a). To distinguish topicalization with left-dislocation, it can be seen from these two sentences.

(16b) The steak, Ed grilled it.

(16c) Ed, he grilled the steak.

Sentence (16b) and (16c) illustrates the examples of left-dislocation of which the dislocated constituent (the steak and $E d$ ) has the pronominal 
copies left in their canonical position (it as the object, he as the subject). Topicalization as in sentence (16a) has no pronominal copy to occupy the empty position left by the constituent.

The relation between the antecedent and the pronominal copy is bound by the constraint in which the antecedent cannot be the clause mate of the pronominal copy. In addition, antecedent cannot c-command the pronominal copy. The following tree diagram shows the illustration of the relationship.

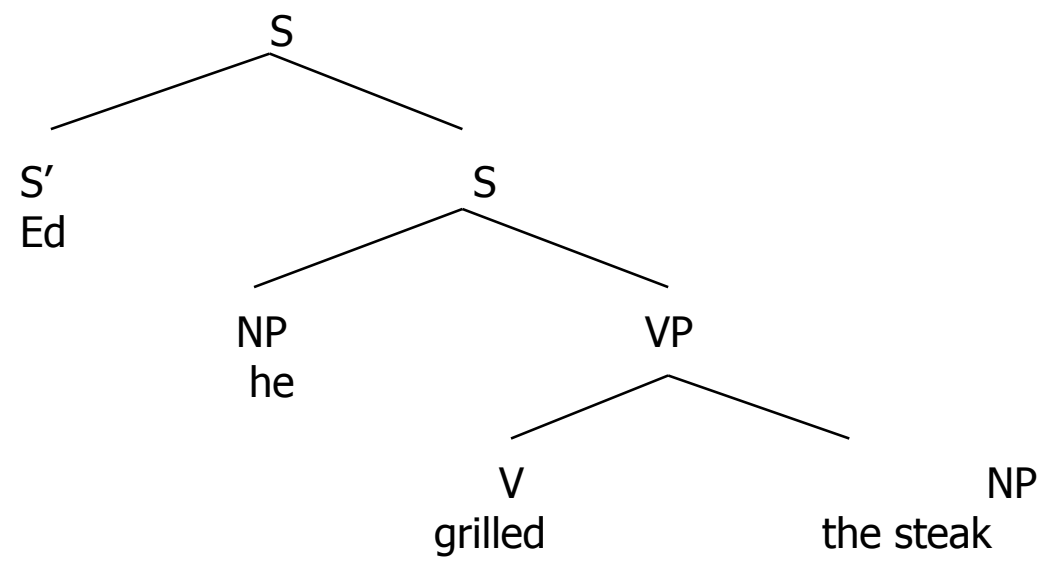

NP Ed is under the $\mathrm{S}^{\prime}$ node that is not the clause mate of $\mathrm{S}$ 'he grilled the steak' which result in the incapability of Ed to c-command the NP he.

Even though left-dislocation involves leftward movement, Barner and Ward (1998) mentioned that it cannot be categorized as constituent with preposing movement, the same as topicalization. There are two main reasons. First, topicalization and left-dislocation are syntactically different. As stated by Creswell (2004), left-disclocation differs from topicalization since it involves the pronominal copying to occupy the empty canonical position in the sentence.

Second, topicalization is limited to the highlight of old or given information (discourse old). On the other hand, left-dislocation can also dislocate discourse new-hearer new information to the left position.

(26) My sister got stabbed. She died. Two of my sisters were living together on Main Street. They had gone to bed, and this man, their girlfriend's husband, came in. He started fussing with my sister and she started to scream. The landlady, she went up and he laid her out. (Welcomat, 12/2/1981)

NP The landlady is new information because it has no place (antecedent) in the previous context or discourse and it is not a general knowledge. But, left-dislocation is possible to introduce new information to the discourse. This kind of left-dislocation is called simplifying left-dislocation (Prince, 1997). Oktavianti (2011) stated that this kind of left-dislocation 
can directly introduce new information without the assistance of the given one, as in the following example.

\section{(27) Siapa yang membeli buku itu? \\ (27a) Yang membeli buku itu (adalah) Lisa.}

Sentence (27a) is the canonical construction as the answer of sentence (27) of which the given information comes first and it is followed by the new one (Lisa). However, the new information can also be proposed in the sentence-initial position as in (27b).

(27b) Lisa, dia yang membeli buku itu.

Sentence (27b) shows that new information Lisa can be introduced to the discourse directly without the repetition of given information (yang membeli buku itu).

4) Right-dislocation

Right-dislocation is the placement of the dislocated constituent to the postverbal position, usually-though not always-sentence-final position (Birner and Ward, 1998). The structure of the construction is similar to left-dislocation, but the constituent is moved to the right position of the sentence, with the pronominal copy occupies the canonical position of the dislocated NP.

(28) They really were enormous, those pipes.

(29) She's a smart cookie, that Diana!

(30) It's very delicate, the lawn.

In sentence (28), those pipes are the canonical subject which is moved or moved to the sentence-final position and there is NP they as the pronominal copy in its canonical position. The same thing happens to sentence (29) and (30) in which Diana and the lawn are moved and replaced by their copies in the canonical position. The following sentences are the canonical construction of each sentence above.

(28a) Those pipes were enormous.

(29a) Diana is a smart cookie.

(30a) The lawn is very delicate.

5) Cleft and pseudo-cleft construction

Cleft and pseudo-cleft express a relationship of identity between the elements realized as the highlighted elements and the relative clause (Collins, 2002:2). Cleft consists of two parts: the open proposition-the presupposition of the utterance-and the focus (Birner and Ward via Aarts and McMahon, 2006). The open proposition shows the presupposition or

Noncanonical Constructions in English and How They Work to Package 
the shared knowledge between speaker and hearer. It is in the form of relative clause. Meanwhile, the focus represents new information so that it is the highlighted element. Below is the noncleft sentence.

(31) Tom offered Sue a sherry.

From the canonical or noncleft sentence above, there are cleft and pseudo-cleft constructions as the noncanonical forms as in (31a) and (31b).

(31a) What Tom offered Sue was a sherry.

(31b) It was a sherry that Tom offered Sue.

Sentence (31a) is the pseudo-cleft construction with What Tom offered Sue as the relative clause (the open proposition) and a sherry as the highlighted element (the focus). In sentence (31b), the highlighted element is a sherry and the relative clause is that Tom offered Sue. Both constructions consider a sherry as the highlighted element. Yet, the highlighted element may vary based on the speaker's emphasis.

(31c) It was Tom who offered Sue a sherry.

(31d) Who was offered Sue a sherry was Tom.

Sentence (31c) and (31d) have different focus compare to sentence (31a) and (31b). The focus in two sentences above is Tom (no longer a sherry).

\section{v. Conclusion}

Based on the explanation above, it is obvious that each language possesses its own information packaging, including English language. English has various constructions called as noncanonical constructions to arrange the information in certain position according to speaker's need or choice. Noncanonical constructions can be produced by preposing or postposing the NPs (information) such as topicalization, cleft/pseudo-cleft construction, and existential there. Furthermore, it can be formed by reversing the argument as in by-phrase passive. To mention some, there are topicalization, existential there, left-dislocation, right-dislocation, and cleft/pseudo-cleft construction as the examples of noncanonical constructions in English. Besides, there are also left-dislocation and rightdislocation which are not included in either preposing or postposing. Each noncanonical construction arranges the information with certain constrain, such as topicalization cannot introduce new information, different from left-dislocation that can dislocate its new information. Nevertheless, further studies on information structure, particularly on noncanonical constructions are still needed to improve the previous ones so that there will be more comprehensive discussion on this topic. 


\section{References}

Aarts, Bas, and April McMahon. 2006. The Handbook of English Linguistics. Oxford: Blackwell Publishing

Birner, Betty J. and Gregory Ward. 1998. Information Status and Noncanonical Word Order in English. Amsterdam: John Benjamin

Chafe, William L. 1976. "Givenness, Contrastiveness, Definiteness, Subjects, Topics, and Point of View." In Charles Li, (ed.), Subject and Topic. New York: Academic Press, 25-55

Collins, Peter C. 1991. Cleft and Pseudo-Cleft Construction in English. London: Routledge

Comorovski, Ileana, and Klaus von Heusinger. 2007. Existence: Semantics and Syntax. Dodrecht: Springer

Comrie, Bernard. 1981. Linguistic Typology and Language Universals. Oxford: Blackwell.

Creswell, Casandre. 2004. Syntactic Form and Discourse Function in Natural Language Generation. New York: Routledge.

Crystal, David. 2008. A Dictionary of Linguistics and Phonetics. Oxford: Blackwell Publishing

Finegan, Edward. 2008. Language: Its Structure and Use. Boston: Thomson Higher Education

Oktavianti, Ikmi Nur. 2011. "Dislokasi Kiri dalam Bahasa Indonesia." Kibas Cenderawasih 7.2, 151-166

Prince, Ellen F. 1997. "On the Function of Left-Dislocation in English Discourse." In Akio Kamio, (ed.), Directions in Functional Linguistics. Amsterdam and Philadelphia: John Benjamin, 43-117

Shopen, Timothy (ed.). 2007. Language Typology and Syntactic Description. Cambridge: Cambridge University Press

Vallduvi, Enric. 1992. The Informational Component. New York: Ga 